\title{
Multispark Discharge in Water as a Method of Environmental Sustainability Problems Solution
}

\author{
E. M. Barkhudarov, ${ }^{1}$ I. A. Kossyi, ${ }^{1}$ Yu. N. Kozlov, ${ }^{2}$ S. M. Temchin, ${ }^{1}$ \\ M. I. Taktakishvili, ${ }^{1}$ and Nick Christofi ${ }^{3}$ \\ ${ }^{1}$ A.M. Prokhorov General Physics Institute of RAS (GPI RAS), Vavilov Street 38, Moscow 119991, Russia \\ ${ }^{2}$ Semenov Institute of Chemical Physics of RAS, Kosygin Street 4, Moscow 119991, Russia \\ ${ }^{3}$ Edinburgh Napier University, Edinburgh EH9 3JF, UK
}

Correspondence should be addressed to I. A. Kossyi; kossyi@fpl.gpi.ru

Received 1 February 2013; Accepted 20 April 2013

Academic Editor: Elena Tatarova

Copyright (C) 2013 E. M. Barkhudarov et al. This is an open access article distributed under the Creative Commons Attribution License, which permits unrestricted use, distribution, and reproduction in any medium, provided the original work is properly cited.

Multispark discharge excited in water is described, and its useful physical and chemical properties are discussed in the light of some environmental issues. Discharge of such a type generates hot and dense plasmoids producing intense biologically active UV radiation and chemically active radicals, atoms, and molecules. Simultaneously, discharge creates strong hydrodynamic perturbations and cavitation bubbles. Particular attention is given to factors influencing on water purity with special reference to discharge application for effective sterilization of water and its cleaning of harmful chemicals. The gas discharges of this type show considerable promise as a means for solving some actual plasma-chemical problems. The above-mentioned discharge properties have been demonstrated in a series of laboratory experiments, which proved the efficiency of disinfection of potable and waste water, water cleaning of pesticide (herbicide) contaminations, and conversion (recovery) of natural methane.

\section{Introduction}

High voltage electric discharge in water $[1,2]$ has been considered as a potential method of water treatment to kill microorganisms and to clean it of harmful contaminations negating the use of chemicals that leads to by-products which may additionally compromise human health [3-5]. Factors favoring their use include the generation of UV radiation, acoustic, shock waves, chemically active substances, cavitation processes, pyrolysis, and hydrolysis. There are also possible synergetic effects following physical and chemical reactions.

Among the different means of in-liquid electric discharge, a novel method involves multielectrode (multispark) slipping (gliding) discharges (SSDs) [6] which may have some advantages over the two-electrode systems generally used at present $[1,7]$.

The present work describes the construction of a multispark discharger and discusses results of experimental investigation of SSD-based methods of water disinfection and their application in plasma-chemical technology for solving some of environmental problems, such as conversion (recovery) of methane (as well as other natural hydrocarbons), and water cleaning of pesticide (herbicide) contamination.

\section{Treatment System}

The apparatus used to treat liquids is shown schematically in Figures 1 and 2 . The basic components were a chamber filled with water, a multielectrode system for exciting of slipping surface discharge, and high voltage power supply (Figure 1). The multielectrode discharge system (Figure 2) was similar in design to that previously described in $[6,8,9]$. The discharger consisted of a set of annular electrodes mounted on a dielectric tube surrounding a back-current conductor. A gas (air, argon, oxygen, etc.) was injected through a set of holes into water between the electrodes, producing fine gas bubbles. Discharge in each interelectrode gap was produced throughout the system, including the metal electrodes, a dielectric substrate, a gas bubble, and water. 


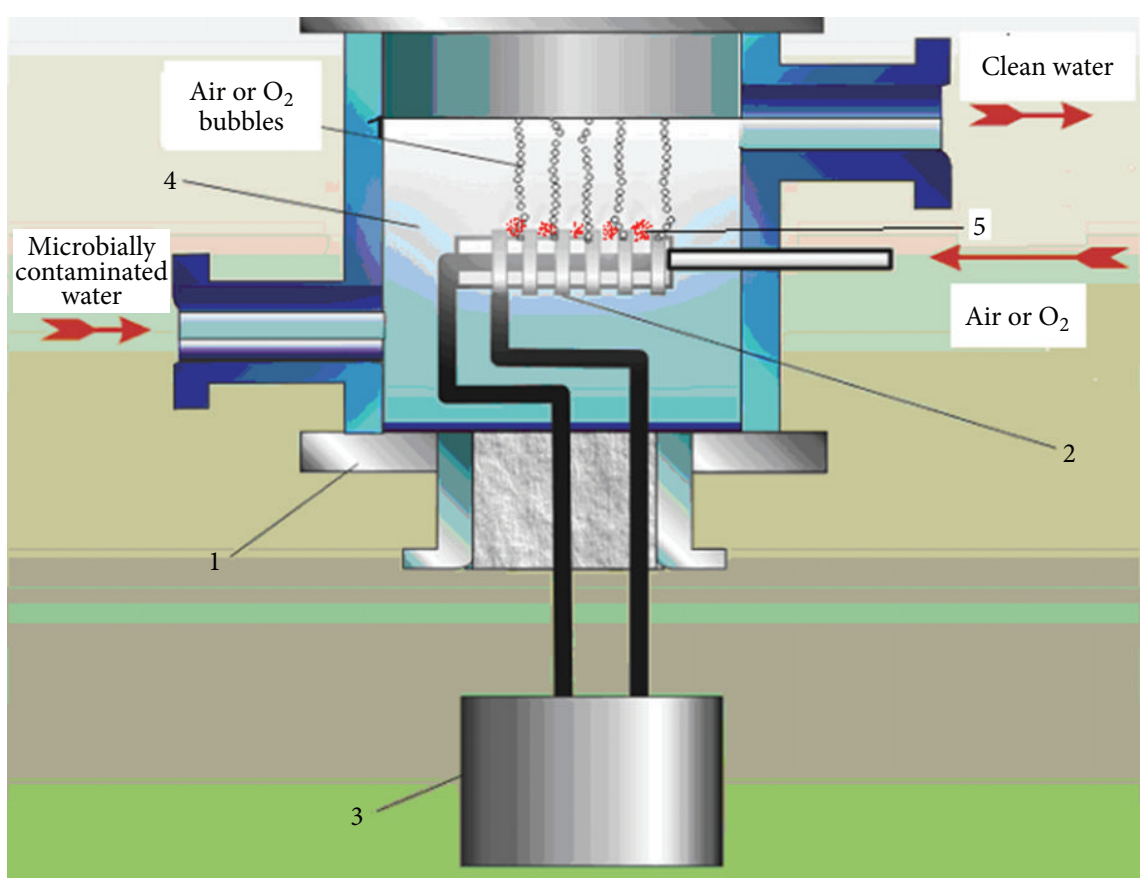

FIGURE 1: Scheme of multispark discharge disinfection of water. (1) Chamber; (2) multispark discharger; (3) generator of high voltage pulses; (4) cleaning water; (5) plasma of gliding discharge.

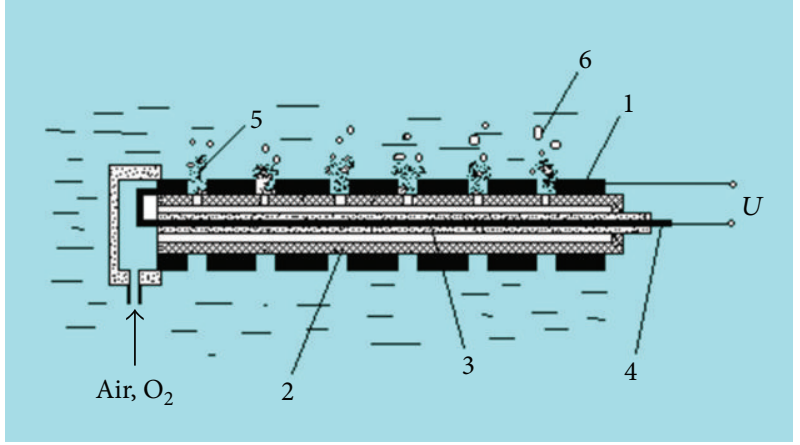

(a)

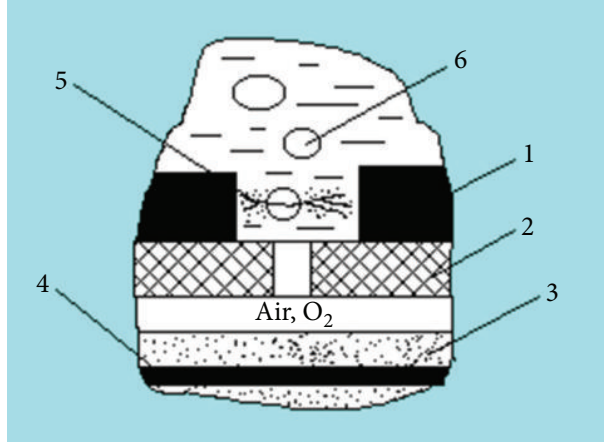

(b)

FIGURE 2: Multielectrode gliding surface discharge facility. (1) Electrodes; (2, 3) dielectric tube; (4) back-current rod; (5) discharge plasma; (6) gas bubbles.

The initial plasma channel may be thought as originating in ordinary gas discharge in a gas bubble if the electric field therein is higher than the gas breakdown threshold $[10,11]$. But in actual fact, a large (sometimes dominant) part in the interelectrode plasma formation could be played by a gliding discharge along the dielectric surface with the subsequent interaction of discharge plasma with electrodes and explosive microplasma production on their surface [12] (see Figure 3). There are just these processes that have been considered to be operative in the case when multispark discharger works in the gas medium [13].

When the high voltage pulse is applied to the immersed in the aqueous medium discharger (shown in Figure 2), plasma bunches (plasmoids) appear almost simultaneously between electrodes. Reasoning from their characteristics these plasmoids can be classified (in accordance with the recently adopted terminology) as "microplasma" formations, involved in various applications [14]. According to the results of previously performed experiments, the electron density in plasmoids attains $10^{17} \mathrm{~cm}^{-3}$, and the gas temperature 4000$5000 \mathrm{~K}$ [15]. According to [16], explosive metallic plasma is a source of intensive hard UV radiation.

A typical photograph of the operating system is shown in Figure 4 .

The principal advantage of the multispark system lies in the following peculiarities of their construction.

(i) The area of the surface of all electrodes contacting water in the multielectrode version can be minimized by introducing insulating dielectric screens ensuring the SSD operation in high-conducting water (up to conductivities of $10^{4} \mu \mathrm{S} \mathrm{cm}^{-1}$ ) without substantial 


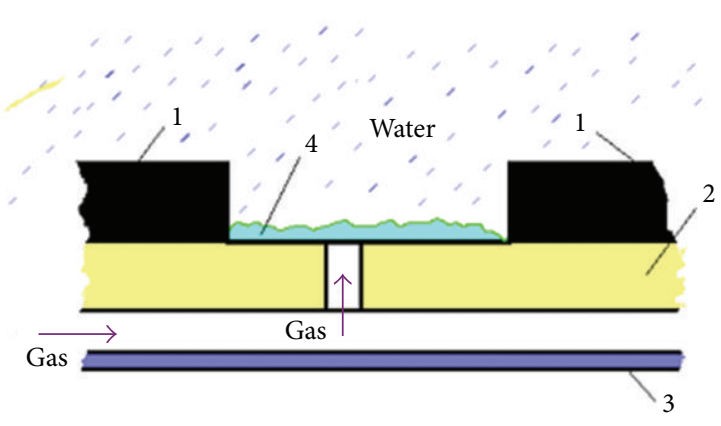

(a)

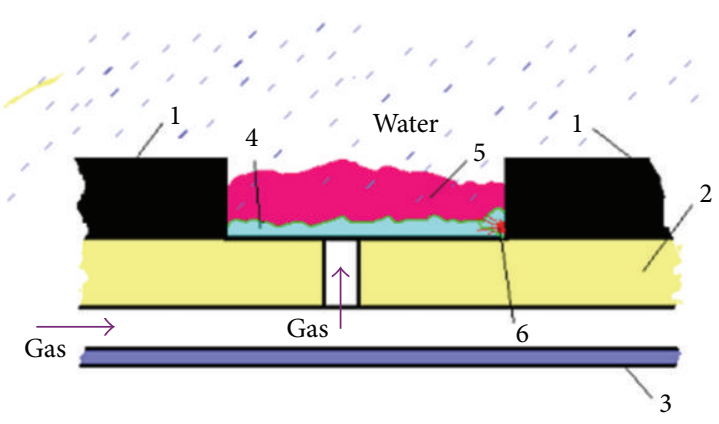

(b)

Figure 3: Two consecutive phases of plasma production in each interelectrode gap. (1) Electrodes; (2) dielectric tube; (3) back-current rod; (4) gliding surface discharge; (5) metallic plasma; (6) unipolar arc.

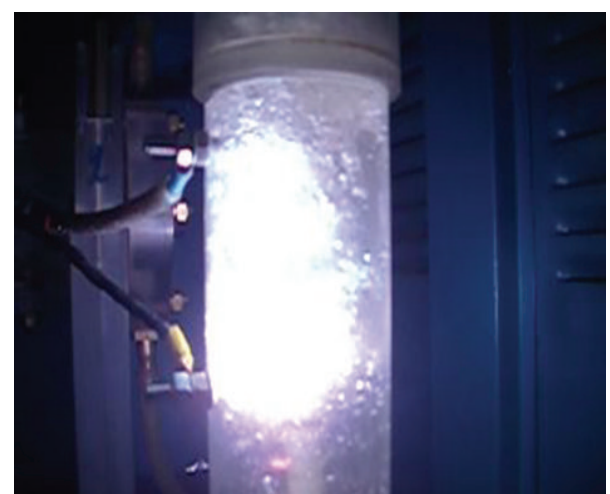

FIGURE 4: Typical photograph of multispark discharger operating in water.

reduction of the efficiency of energy supply to the discharge region.

(ii) The discharger has no pointed electrodes; the working surface of the electrodes (unprotected by dielectric screens) is developed and is either a part of cylindrical surface of tubular electrodes or the plane surface at the exit sections of the tube. Thus, the principal advantage of SSD system lies in the decrease in the discharge load of each electrode (thereby enhancing the erosion resistance on the system as a whole), which ultimately substantially increases the lifetime of the system.

(iii) The dischargers can affect the aqueous (liquid) medium through several simultaneously acting mechanisms, among them the direct influence of discharge plasma, the action of UV radiation generated by microscopic discharges, the chemical action of chemically active radicals, atoms, and molecules produced in discharges, and the hydrodynamic action through microscopic cavitation bubbles.

(iv) Cleansing action and bactericidal effect of a multispark discharge in the water medium unessentially depend on electrode material. Nevertheless among the tested metals (Fe, $\mathrm{Mo}, \mathrm{Cu}, \mathrm{Ti}$, etc.), just stainless steel and titanium have been selected as materials exhibiting the most promise for working as a detail of multispark discharger. Just these two metals have been used in electrodischarge systems applied in the General Physics Institute (GPI RAS) for solution of water purification problems.

(v) The discharge gaps could be distributed in such a way as to increase the efficiency of the discharge action on liquids, in particular, by focusing the shock waves and UV radiation flux [17].

The experiments were conducted using the high voltage multichannel ( 5 channels) generator with the following parameters: high voltage amplitude, $U \leq 20 \mathrm{kV}$; pulse repetition frequency, $f \leq 100 \mathrm{~Hz}$; capacitive storage energy of one channel, $W \leq 2 \mathrm{~J}$, and pulse duration, $\tau \approx 5 \mu \mathrm{s}$. The circuit of the output stage of each channel is shown in Figure 5. Each multispark discharger was powered from one channel of a multichannel generator. The discharge current and voltage were measured with the aid of a Rogowski coil and voltage divider. The signals shown on the Figure 6 were recorded with an oscilloscope (TDS 3012). These measurements allowed the determination of the energy density $\left(\mathrm{J} \mathrm{cm}^{-3}\right)$ released in liquid.

\section{Multispark Electric Discharge in Water as a Source of UV Radiation, Ozone, and Hydrogen Peroxide}

Figure 7 shows a schematic of the experiment intended to investigate a multispark SSD in water as a source of UV radiation, ozone, and hydrogen peroxide. Multielectrode discharger (2) is positioned in a cell (1) with water. A high voltage pulse produces a plasma channel between the electrodes. The gas leaving the reactor (as a working gas air or oxygen has been applied) flows into a quartz cell (3) intended for determining the ozone content by the method of absorption spectroscopy. In the course of the experiments, the production of $\mathrm{H}_{2} \mathrm{O}_{2}$ was also measured. UV radiation was measured in the presence and absence of water in the reactor chamber. 


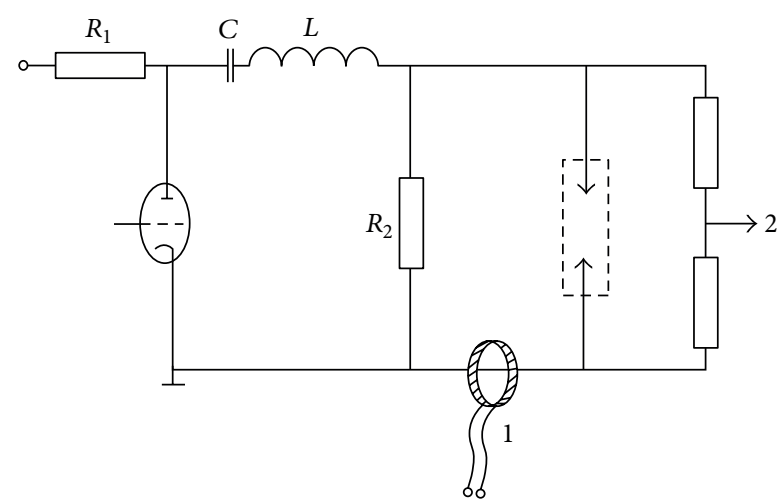

Figure 5: Output stage of one channel of the high voltage pulses power supply. (1) Rogowski coil; (2) voltage divider. $R_{1}, R_{2}$-resistors; $C$-capacitor; $L$-inductor.

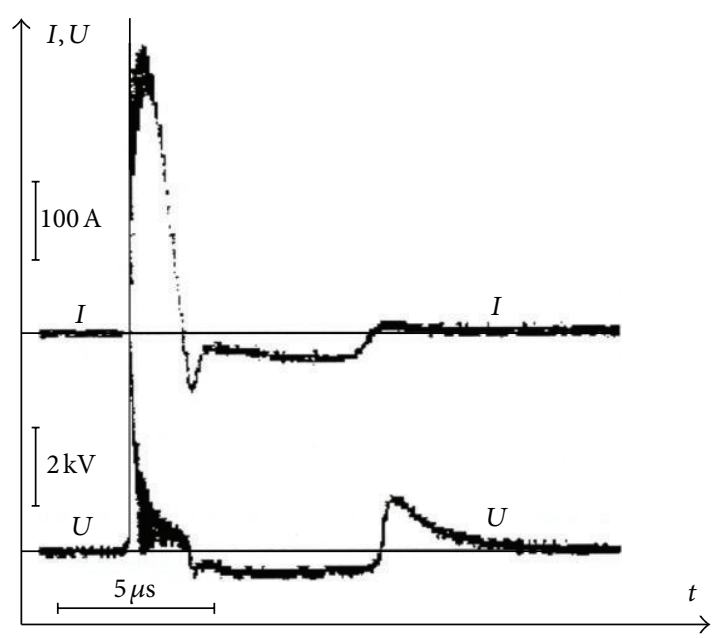

FIGURE 6: Typical oscillograph trace of SSD current and voltage.

The discharge emission spectrum in the region $230<$ $\lambda_{d}<300 \mathrm{~nm}$ was measured with the help of an MUM-1 monochromator ((8), Figure 7) and with an FEU-142 photomultiplier. Typical spectra of UV emission from the discharge are shown in Figure 8.

Chemical (actinometric) measurements have been used as well. In this case, the UV intensity was deduced from photolysis of an irradiated $\mathrm{K}_{3} \mathrm{Fe}\left(\mathrm{C}_{2} \mathrm{O}_{4}\right)_{3}$ solution with a phenanthroline admixture.

This technique was described in [18] and successfully used in [13] to study the multispark discharge in gaseous (Ar) medium.

To measure the $\mathrm{O}_{3}$ content in the gas flowing from the reactor, we used both spectroscopic and chemical methods. The scheme of measurements of the $\mathrm{O}_{3}$ content in $\mathrm{O}_{2}$ is shown in Figure 7. From attenuation of the UV radiation passing through the cell, the $\mathrm{O}_{3}$ density in the gas was determined by the absorption method. The spectral interval used to determine the ozone content corresponded to the Hartley absorption band with the maximum near $\lambda_{d} \cong$ $255.5 \mathrm{~nm}$

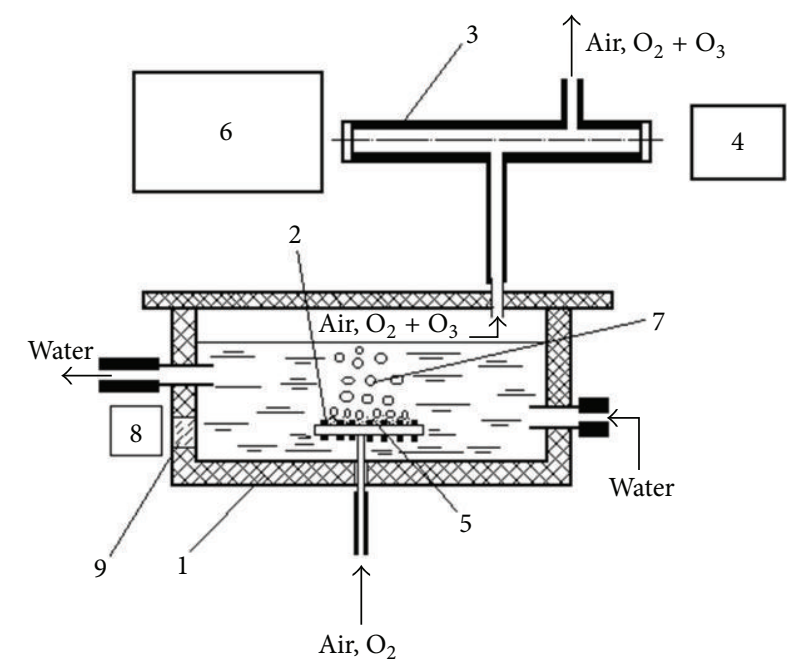

FIGURE 7: Experimental layout. (1) Vessel filled with water; (2) multispark discharger; (3) diagnostic quartz cell; (4) deuterium lamp; (5) discharge plasma; (6) MDR-3 monochromator; (7) gas bubbles; (8) MUM-1 monochromator; and (9) quartz window.

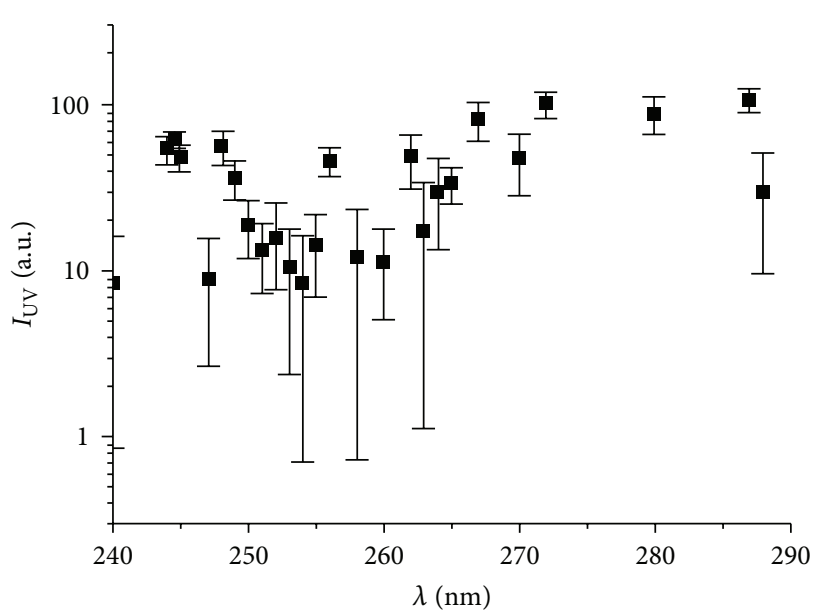

FIGURE 8: Spectrum of soft UV radiation from multispark discharge in the water.

In the case of application of air as working gas, the $\mathrm{O}_{3}$ content was determined by the chemical method from the reaction between $\mathrm{O}_{3}$ and potassium iodide in the water solution [19].

Figure 9 shows the ozone density in the diagnostic cell as a function of the repetition frequency of high voltage pulses $(f)$ for a discharge in water (for various oxygen flow rates). Restriction of $f$ values by amounts of the order of $100 \mathrm{~Hz}$ is not critical and appears explicable only on the basis of improper technical equipment of laboratory.

In the experiments when the oxygen flow rate through the interelectrode gaps and the water-filled reactor was $w \cong$ $15 \mathrm{~L} / \mathrm{min}$, the ozone density in the oxygen flow was equal to $n_{\mathrm{O}_{3}} \cong(1-2) 10^{15} \mathrm{~cm}^{-3}$.

The $\mathrm{H}_{2} \mathrm{O}_{2}$ content in water treated by the electric discharge was measured by the iodide-molybdate method 


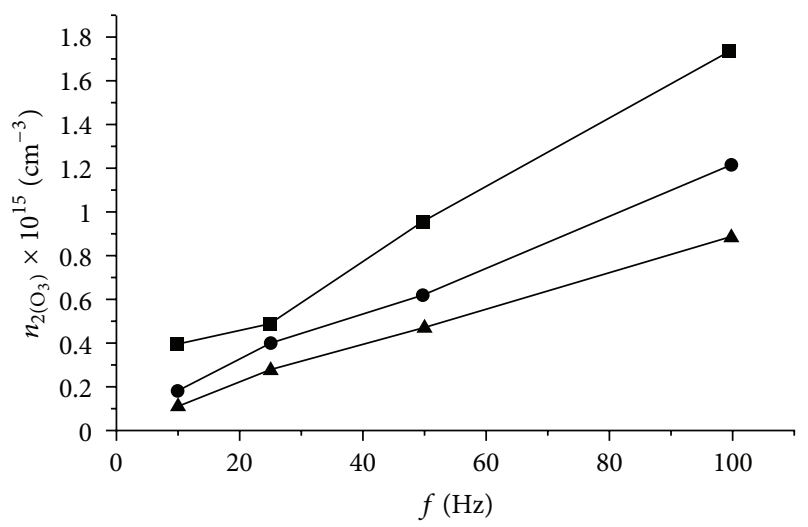

FIGURE 9: Ozone density in the diagnostic cell as a function of the repetition frequency of multispark discharge in the tap water for various flow rates of $\mathrm{O}_{2}:-w=10 \mathrm{~L} \mathrm{~min}^{-1} ;-15 \mathrm{~L} \mathrm{~min}^{-1} ; \mathbf{\Delta}-$ $20 \mathrm{~L} \mathrm{~min}^{-1}$.

described in [20] and used in [13] to determine the intensity of hard UV radiation of the gliding surface discharge in argon.

The measurements of hydrogen peroxide production that were carried out in a discharge in water with injected argon showed that a series of discharges for 6-7 minutes in $250 \mathrm{~cm}^{3}$ of water produced $\mathrm{H}_{2} \mathrm{O}_{2}$ with a mean density of $n_{\mathrm{H}_{2} \mathrm{O}_{2}} \cong 2$. $10^{-3} \mathrm{~mol} \mathrm{~L}^{-1} \cong 1.2 \cdot 10^{18} \mathrm{~cm}^{-3}$. The energy cost of production of one $\mathrm{H}_{2} \mathrm{O}_{2}$ molecule in this case is $h_{\mathrm{H}_{2} \mathrm{O}_{2}} \leq 1.5 \cdot 10^{2} \mathrm{eV} / \mathrm{mol}$.

The performed experiments demonstrated that for the SSD in the water-gas mixture, at least two factors are realized among the factors that are usually invoked to explain the sterilization effect of electric discharges. These are the generation of UV radiation and the production of biologically active ozone and hydrogen peroxide.

It is possible to estimate, using the results of measurements, the effectiveness of these two factors in the degradation of microorganisms during operation of the electricdischarge systems under study.

Examining the UV radiation from the discharge, we have to take into consideration that according to [21] the strongest bactericidal effect is produced by ultraviolet rays with wavelengths from 295 to $220 \mathrm{~nm}$ (the "bactericidal" spectral region).

Measurements performed in our work (see [9]) showed that the radiation spectrum of the multispark discharge in water contains the biologically active component, and the intensity of this component increases substantially as the pulse energy increases.

Based on the results of absolute measurements of UV radiation by the actinometric method, we estimate the intensity of the flux of bactericidal rays per pulse discharge as $P_{\mathrm{UV}(i)} \approx 3 \cdot 10^{6} \mu \mathrm{W} / \mathrm{cm}^{2}[9]$.

Given this intensity, in turn, the effectiveness of the action of radiation on E. coli bacteria can be estimated from the known relation [21]

$$
n_{b} \cong n_{b 0} \exp \left(\frac{-P_{\mathrm{UV}} t_{a}}{k_{b}}\right),
$$

where $n_{b}$ is the number of bacteria in a unit volume that remain living after bactericidal irradiation $\left(\mathrm{cm}^{-3}\right), n_{b 0}$ is the initial number of bacteria in a unit volume $\left(\mathrm{cm}^{-3}\right), P_{\mathrm{UV}}$ is the mean intensity of the flux of bactericidal rays $\left(\mu \mathrm{W} \mathrm{cm}{ }^{-2}\right)$, $t_{a}$ is the irradiation time (s), and $k_{b}=2500$ is the bacterial tolerance factor.

For the case of repetitive discharge, expression (1) can be rewritten in the form

$$
n_{b} \cong n_{b 0} \exp \left(\frac{-P_{\mathrm{UV}(i)} \tau f t_{a}}{k_{b}}\right),
$$

where $\tau$ is pulse duration (s) and $f$ is the repetition frequency of high voltage pulses $(\mathrm{Hz})$.

It is easy to see that for $P_{\mathrm{UV}(i)} \sim 3 \cdot 10^{6} \mu \mathrm{W} \mathrm{cm}{ }^{-2}, \tau=5 \mu \mathrm{s}$ and $f=100 \mathrm{~Hz}$, the exposure time equal to a few seconds is sufficient to decrease the number of bacteria in water by a factor of ten. This means that the energy cost of treating water by bactericidal UV rays is of the order of $\xi_{\mathrm{UV}} \approx(1-$ 2) $10^{-4} \mathrm{kWh} \mathrm{L} \mathrm{L}^{-1}$.

Under the experimental arrangement shown in Figure 7, ozone generated in the discharge has no time to dissolve in water and is almost completely removed by the air (oxygen) flow into the space over the water reactor. In principle, it is possible to construct a reactor such that the produced ozone will be completely "entrapped" in the water being treated. Let us estimate how effective the role of ozone in the sterilization action of discharge may be in this case.

As follows from the data presented in [19], the effect of ozone dissolved in water on microorganisms becomes significantly stronger when the $\mathrm{O}_{3}$ content reaches the threshold level $\left[n_{\mathrm{O}_{3}}\right]_{\text {th }} \cong 8 \cdot 10^{16} \mathrm{~cm}^{-3}$. Over $\left[n_{\mathrm{O}_{3}}\right]_{\text {th }}$, the E. coli bacteria content decreases by more than four orders of magnitude.

It is easy to see that the bactericidal treatment capacity of ozone can be as high as

$$
w_{\mathrm{O}_{3}} \cong \frac{n_{\mathrm{O}_{3}} w_{b}}{\left[n_{\mathrm{O}_{3}}\right]_{\mathrm{th}}} \cong 25 \mathrm{~L} \mathrm{~h}^{-1},
$$

where $w_{\mathrm{O}_{3}}$ is the water-treatment rate $\left(\mathrm{Lh}^{-1}\right)$ and $w_{b}$ is the air flow rate through the discharge facility $\left(\mathrm{L} \mathrm{h}^{-1}\right)$. Then, the energy cost of water treatment by ozone generated in the discharge (assuming that it is completely dissolved in water) can reach $\xi_{\mathrm{O}_{3}} \cong 3 \cdot 10^{-4} \mathrm{~kW} \mathrm{~h} \mathrm{~L}-1$ which is comparable with the energy cost of sterilization by UV radiation.

Finally, we estimate the effectiveness of a possible bactericidal action of the multispark discharge in water due to the production of hydrogen peroxide. Special microbiological studies carried out by us showed that an addition of hydrogen peroxide as a level of $n_{\mathrm{H}_{2} \mathrm{O}_{2}} \sim 10^{17} \mathrm{~cm}^{-3}$ to tap water allows the number of $E$. coli bacteria to be reduced by one order of magnitude. This means that the experimentally measured rate of $\mathrm{H}_{2} \mathrm{O}_{2}$ production ensures the energy cost of water sterilization at the level $\xi_{\mathrm{H}_{2} \mathrm{O}_{2}} \sim 10^{-4} \mathrm{~kW} \mathrm{~h} \mathrm{~L}^{-1}$, which is close to the energy cost of sterilization by ozone production in discharge.

Hence, the performed direct measurements of UV radiation and chemically active products evidence that described below multispark slipping surface discharge (SSD) in water with air as an working gas is promising for water sterilization since two effects only, examined in our work, can ensure the 
energy cost as low as $\xi \cong 10^{-4} \mathrm{~kW} \mathrm{~h} \mathrm{~L}^{-1}$ for reducing the $E$. coli bacteria content by one order of magnitude (i.e., with a generator with a mean power of $1 \mathrm{~kW}$, it is possible to reach a water treatment rate of the order of $10 \mathrm{~m}^{3} \mathrm{~h}^{-1}$ ).

It should be pointed out that possibility to apply for multispark discharger excitation of practically every gas or gaseous mixtures offers great opportunities for action on a microbiological component through the different chemically active atoms and radicals. However, in this work authors have restricted for water sterilization by the application only of air or oxygen taking into account that based on application of these gases discharger will be simplex and cheapest.

\section{Multispark Electric Discharge Disinfection of Microbially Contaminated Liquids}

As a step of our activity experimental investigation of effectiveness of disinfection action of multispark discharge on the water containing Escherichia coli and its viruses (coliphages) has been carried out [22].

The apparatus used to treat liquids is the same as shown schematically in Figure 1 . The discharge devicemultispark discharger-was situated in the treatment chamber through which water contaminated with microorganisms was pumped. Water contaminated with E. coli or viruses (somatic coliphages) can be used to test the killing efficiencies of the discharge system. Samples of water for microbiological analyses were taken via a sampling port; triplicate samples in $10 \mathrm{~mL}$ sterile bottles being removed for analysis.

Escherichia coli (NCIMB 86; ATCC 4157) was grown overnight in nutrient broth (oxoid) at $37^{\circ} \mathrm{C}$. The cultures were diluted to population densities of approximately $10^{6} \mathrm{cfu} \mathrm{mL}^{-1}$ with tap water and placed in treatment chamber containing the multispark discharger.

Water samples treated by the electric discharges were removed from the system at varying time intervals and bacterial killing assessed using spread plate counting methodology. Escherichia coli was determined by spreading $100 \mu \mathrm{L}$ aliquots of diluted samples onto nutrient agar plates. Occasionally, MacConcey agar (HMSO 1994) and a spiral platter were utilized. Replicate plates were incubated at $37^{\circ} \mathrm{C}$ for $24 \mathrm{~h}$. Coliphages were estimated by a plaque assay utilizing $E$. coli $C$ (ATCC 13706) as the host bacterium. Dilutions of treated samples were spread onto lawns of $E$. coli $C$, sensitive to a broad spectrum of coliphages, and the number of plaques formed after $24 \mathrm{~h}$ incubation counted.

Figure 10 shows the effect of multispark discharges on microorganisms in the water. The fraction of surviving bacteria and viruses $\left(N / N_{0}\right)$ is plotted versus the energy density $\left(\mathrm{J} \mathrm{cm}^{-3}\right)$ released in water. Each point in the plot presents the mean of three measurements. Deviation from the mean did not exceed $15 \%$. Numerous experiments were carried out using E. coli, and all showed a similar killing efficiency of the multispark discharge system. Data of microbial killing in liquids containing tap water-microbe combinations and a conductivity of $100 \mu \mathrm{S} \mathrm{cm}^{-1}$ are presented. It is evident from Figure 10 that the viruses were killed using a lower energy input to the liquid. Escherichia coli required an energy input

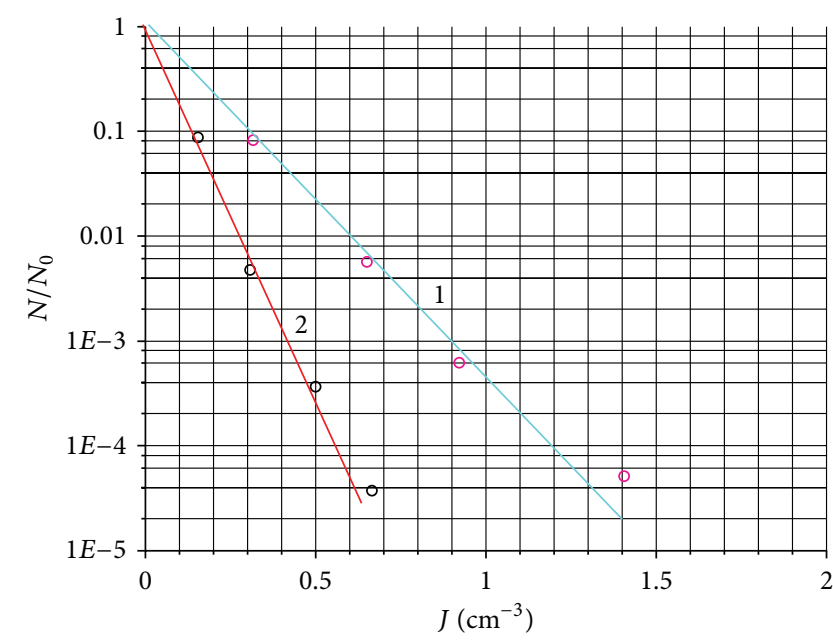

FIGURE 10: Changes in populations of Escherichia coli and viruses $(N)$ in treated water relative to the initial populations $\left(N_{0}\right)$ as a function of specific energy release $\left(\mathrm{J} \mathrm{cm}^{-3}\right)$ during the treatment. Potable water with a conductivity $\sigma=100 \mu \mathrm{S} \mathrm{cm}^{-1}$ was used. $f=$ $10 \mathrm{~Hz}$. The initial $\left(N_{0}\right)$ concentration of $E$. coli was $\approx 10^{6}$ colonyforming units $\mathrm{mL}^{-1}$ and that of coliphages $\approx 10^{7}$ plaque-forming units $\mathrm{mL}^{-1}$. (1) E. coli; (2) coliphages.

of $0.3 \mathrm{~J} \mathrm{~cm}^{-3}$ (approx. $10^{-4} \mathrm{~kW} \mathrm{~h} \mathrm{~L}^{-1}$ ) to reduce the population by a factor 10 (1log reduction) while coliphages required an energy input of $0.15 \mathrm{~J} \mathrm{~cm}^{-3}$ for the same result.

The used multispark discharger regimes are identical with the regimes previously investigated [9] where an examination was made of the generation of biologically active UV radiation, ozone, hydrogen peroxide, and other active species (see preceding section of this paper). Measurements carried out during the present study allowed calculation of energy costs of the disinfection action using multispark electric dischargers, and these were as low as $10^{-4} \mathrm{~kW} \mathrm{~h} \mathrm{~L}^{-1}$ for bacteria. These values verified the bacterial action of discharges in the water predicted in the preceding section and confirmed that the main factors affecting microbial destruction in the water were UV radiation and the production of biologically active chemicals. The latter are not involved in treatment systems utilizing UV lamps which would be unable to generate highly reactive chemical species. Acoustic and shock waves generated by multispark discharge also played a part in microbial disinfection but, in addition, they facilitated the mixing of treated water, delivering reactive chemical species to all parts of the treatment system.

The possibility that disinfection using electric discharges might lead to the production of toxic by-products was tested by the input of energy as high as $\sim 1 \mathrm{~J} \mathrm{~cm}^{-3}$ into water. Water samples were analyzed for a range of substances and physical appearance by the Certification Control-Analytical Center (Moscow State University, Russia). The water was tested for color, turbidity, $\mathrm{pH}$, ammonium, $\mathrm{Fe}, \mathrm{Pb}, \mathrm{Cr}$, fluorite, chlorite, nitrate, and sulphate. The quality of the treated water fulfilled the necessary standards of the European Union (Council Directives on the quality of water intended for human consumption $80 / 778 /$ EEC and the new drinking water Directive 98/83/EC adopted by the Council on 3 November 1998). The 
results for Fe were particularly important as the electrodes used in the study were manufactured from stainless steel. Erosion of multispark discharger is small and does not affect overall concentrations in water. In addition, incubations of multispark discharge treated water with microorganisms were carried out to test whether the killing action continued. This could be due to the persistence of oxidizing species produced by the discharge but these were rapidly quenched within the system following treatment. There were no increased effects on E. coli added to system containing plasma treated compared with nonplasma-treated tap water. This is contrary to results obtained with two-electrode discharges [1] and could be explained by quite low level of operated multispark discharger electrodes sputtering and as a result extremely low level (in comparison with the twoelectrode system) of content of metallic clusters responsible (according to [1]) for prolonged action of discharge on a microbial population. It is of interest to note that a multispark discharge treatment of short duration could sterilize tap water containing E. coli and coliphage. The duration was short enough for the cost-effective treatment of water supplies $(<5 \mathrm{~min})$; contact time being in the region of minutes rather than the 30 mins used in chlorination.

This study concentrated on verifying the predictions of microbial killing made originally in [9] and utilized E. coli and coliphage as representative organisms. No attempt has been made at this stage to examine the effect of multispark discharge plasma on the other bacteria (Gram-positive or -negative types), viruses, or spores (bacterial or fungal). Preliminary experiments have been performed to determine only the effect of multispark plasma on the oocysts of Cryptosporidium (a protozoan parasite causing gastrointestinal disorders), which are resistant to chlorination. The microscopic examination of cysts after treatment showed cell wall degradation and an inability to induce excystation in the organism.

It is of interest to investigate the possibility of using the multispark system described to treat industrial and domestic wastewater. The first attempt at such an application has been taken in $[8,23]$. Water treatment was carried out using wastewater directly abstracted from final effluent stream at the Livingston Wastewater Treatment Plant in West Lothian, Scotland, UK. The scheme of system for wastewater treatment is shown in Figure 11. Results of SSD action on a final effluent stream are presented in Figure 12. It was shown that a specific energy of $1.25-1.5 \mathrm{~J} \mathrm{~cm}^{-3}$ was required to achieve $1 \log$ reduction in bacterial (faecal coliforms/total aerobic heterotrophs) content. This study has demonstrated the effectiveness of the multispark dischargers in microbial disinfection of wastewater. The system can be engineered to eradicate microbial populations to levels governed by legislation by increasing treatment time or energy input.

\section{Plasma-Chemical Converter of Methane on the Basis of Multielectrode Discharger}

One from the currently important ecological problem consists in utilization of gases accompanying oil recovery. Yearly more than billion cubic meters of associated gases are burning down worldwide. Russian oil producing companies for compensation of an ecological harm are paying near 500 rubles for each $1000 \mathrm{~m}^{3}$ of burning petroleum gas.

Presented work objective is the investigation of possibility of natural hydrocarbons (namely, $\mathrm{CH}_{4}$ ) recovery in plasma-chemical reactor based on the SSD. Traditional for GPI research multispark dischargers have been used with only one key distinctive feature of their construction: as a discharge formative gas methane (or any other utilizable natural hydrocarbons) has been applied.

The diagram of the experiment is shown schematically in Figure 13. A multielectrode discharger is introduced into the reaction chamber in the form of an organic glass vessel filled with water (volume $V \sim 0.25 \mathrm{~L}$ ). When a high-voltage pulse is applied to the discharger, a system of plasma formations (plasmoids) in which the decomposition of hydrocarbons takes place is formed in bubbles of methane or methaneoxygen mixture in the gaps between the electrodes. The source of high voltage pulses was a generator producing single pulses or operating in the pulse-periodic regime. The pulserepetition rate was $f \leq 50 \mathrm{~Hz}$, the pulse duration was $\tau_{p} \approx$ $1 \mu \mathrm{s}$, and the pulse amplitude was $U_{p} \approx 40 \mathrm{kV}$.

We analyzed samples of the gas taken at the outlet of the reaction volume. Analysis of the gas passing through the discharger was carried out using the following techniques:

(i) special ITT IK/VP test tubes (OOO Impul's) used for determining the contents of acetylene $\left(\mathrm{C}_{2} \mathrm{H}_{2}\right)$, carbon dioxide $\left(\mathrm{CO}_{2}\right)$, and carbon monoxide $(\mathrm{CO})$;

(ii) SPECORD IR spectrograph used for determining the acetylene content;

(iii) gas chromatograph used for determining the concentration of methane $\left(\mathrm{CH}_{4}\right)$ and hydrogen $\left(\mathrm{H}_{2}\right)$.

Figure 14 shows the characteristic spectrograms obtained on the SPECORD IR spectrograph. The main absorption lines of $\mathrm{CH}_{4}, \mathrm{C}_{2} \mathrm{H}_{2}$, and $\mathrm{CO}$ can be distinguished (in subsequent analysis of the experimental results, $\mathrm{CO}$ was disregarded). The lines of the nearest unsaturated hydrocarbon ethylene $\mathrm{C}_{2} \mathrm{H}_{4}$ are also very weak (at the noise level). In analysis of the efficiency of the plasma-chemical conversion of methane, it is expedient (see [24]) to use such parameters as the degree of conversion $\alpha$ expressed in fractions (in other words, the fraction of methane fed to the reactor and converted into a certain product at the output) and the energy value $\varepsilon$ of conversion (i.e., the energy value of transformation of methane molecules in $\mathrm{eV} /$ molecule). If we disregard for simplicity the small amounts of ethylene formed as a result of methane treatment, we can assume that mainly two reactions occur in the plasma-chemical reactor: pyrolysis reaction,

$$
\mathrm{CH}_{4} \longrightarrow \mathrm{C}+2 \mathrm{H}_{2}
$$

and the reaction of transformation of methane into acetylene,

$$
2 \mathrm{CH}_{4} \longrightarrow \mathrm{C}_{2} \mathrm{H}_{2}+3 \mathrm{H}_{2}
$$

It can be seen from simplified reaction formulas (4) and (5) that the volume of the reaction products exceeds the 


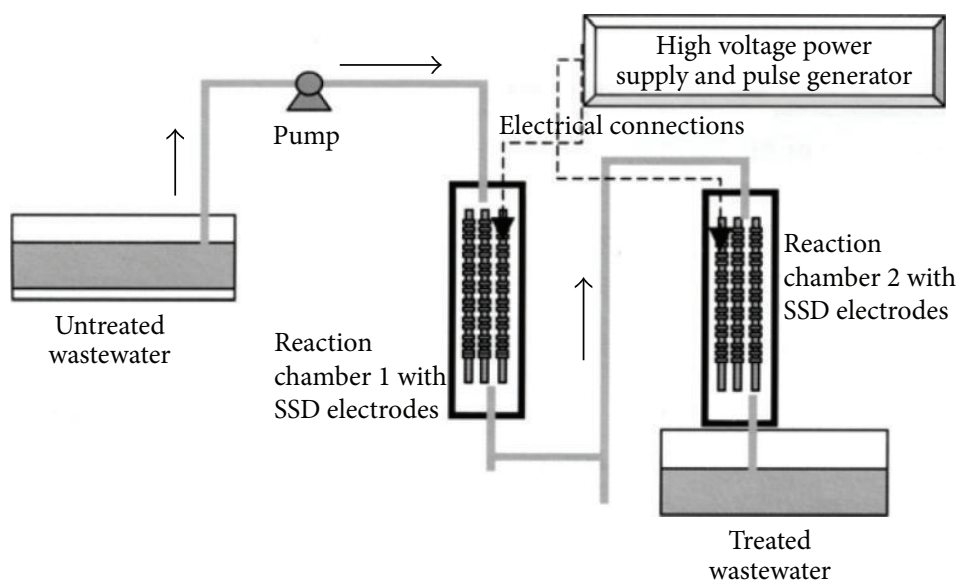

FIGURE 11: Diagrammatic representation of continuous wastewater treatment using system of multispark dischargers.

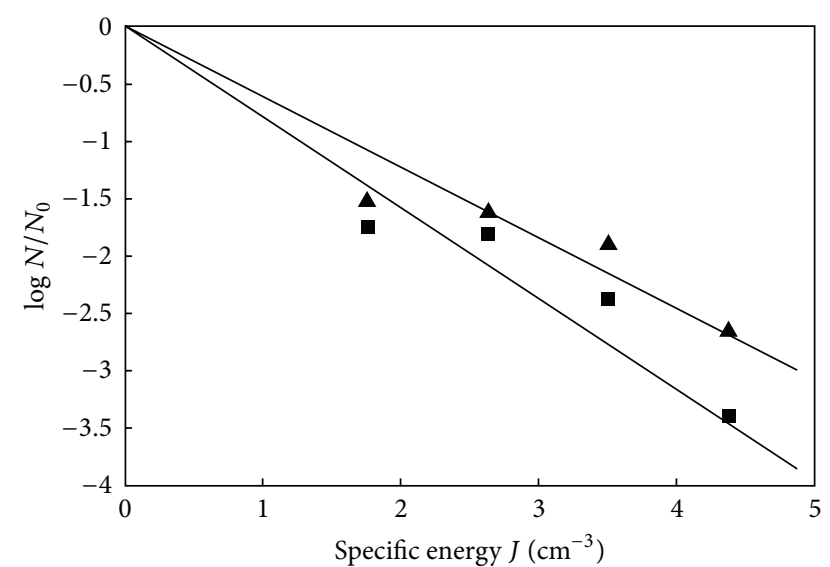

FIGURE 12: Log bacterial population $\left(N / N_{0}\right)$ changes versus specific energy released in water during the multispark discharger operation. $\Delta$-Total aerobic heterotrophic bacteria $\left(22^{\circ} \mathrm{C}\right)$; $\mathbf{\square}$-faecal coliforms $\left(37^{\circ} \mathrm{C}\right)$.

volume of the primary mixture. For this reason, the measurements of concentration of methane and decomposition products at the reactor outlet cannot be directly used for estimating the degree of conversion.

It can easily be shown $[24,25]$ that the degree of conversion $\alpha_{1}$ of methane into carbon and hydrogen according to reaction (4) and the degree of conversion $\alpha_{2}$ of methane into acetylene according to reaction (5) are connected with experimentally determined concentrations $\mathrm{C}_{\mathrm{CH}_{4}}, C_{\mathrm{C}_{2} \mathrm{H}_{2}}$, and $\mathrm{C}_{\mathrm{H}_{2}}$ by the relations

$$
\begin{gathered}
\alpha_{1}=\frac{4 C_{\mathrm{H}_{2}}-3\left(1-C_{\mathrm{CH} 4}\right)}{1+C_{\mathrm{CH}_{4}}}, \\
\alpha_{2}=\frac{4\left(1-C_{\mathrm{H}_{2}}-C_{\mathrm{CH}_{4}}\right)}{1+C_{\mathrm{CH}_{4}}}, \\
\alpha_{0}=\frac{1-C_{\mathrm{CH}_{4}}}{1+C_{\mathrm{CH}_{4}}},
\end{gathered}
$$

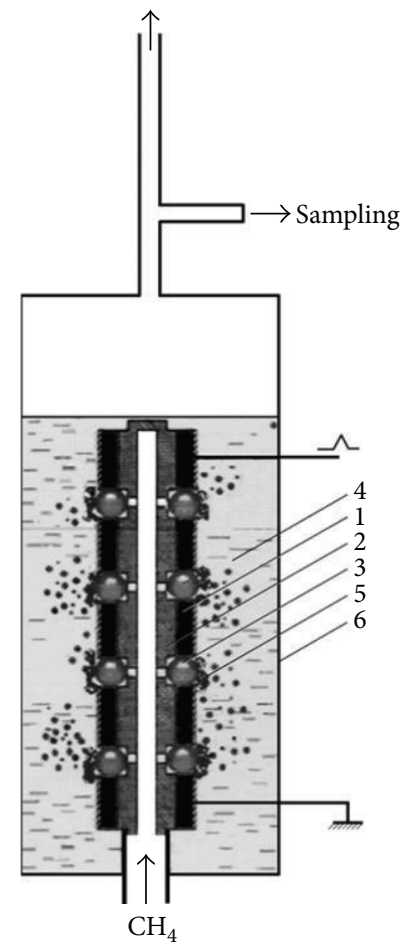

FIGURE 13: Schematic of the experiment. (1) Dielectric tube; (2) annular electrodes; (3) working gas $\left(\mathrm{CH}_{4}\right)$ bubbles; (4) water; (5) plasma in the interelectrode gaps; (6) reaction chamber.

where $\alpha_{0}=\alpha_{1}+\alpha_{2}$ is the total degree of conversion of methane over channels (4) and (5), which is determined in the given experiment.

The energy value of the reaction of decomposition of a methane molecule (in other words, the value of formation of products) is defined by the relation

$$
\varepsilon_{n}=\frac{\bar{P}}{\alpha_{n} q_{\mathrm{CH}_{4}}},
$$




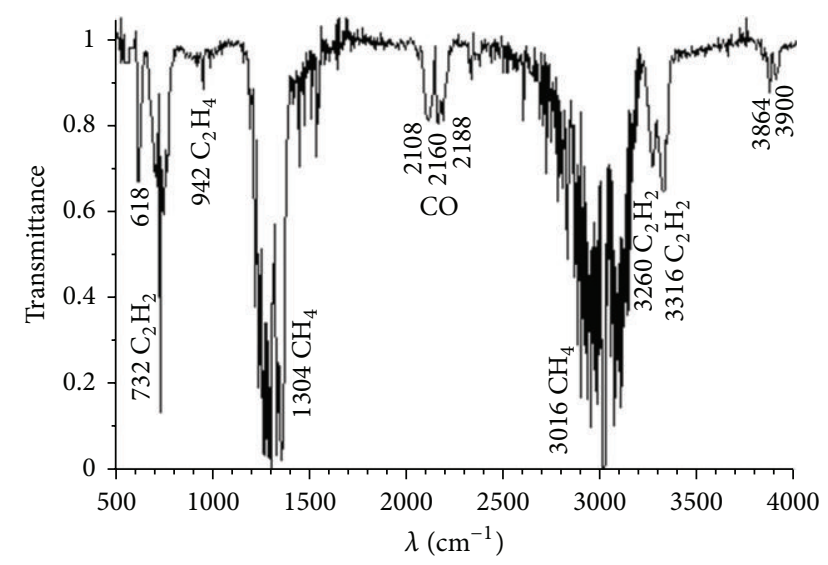

FIGURE 14: Characteristic adsorption IR spectrum of a working gas sample taken at the reactor outlet.

where $n=0,1,2$ is the power supplied to the reactor, $q_{\mathrm{CH}_{4}}$ is the methane flow rate, and $\bar{P}$ is the average microwave power.

The dependences of flow rate $q_{\mathrm{CH}_{4}}$ of methane and of the energy value on its decomposition and the formation of products on the degree of conversion of methane are shown in Figures 15 and 16.

The dependence of the degree of conversion of methane on its flow rate shown in Figure 15 closely fits to the inverse proportionality function

$$
\alpha_{0}=\frac{A}{q_{\mathrm{CH}_{4}}} .
$$

Using iterations, we find that $A=0.02809 \mathrm{~L} / \mathrm{min}$. The fact that experimental points fit well to functional dependence (8) suggests that this dependence is preserved in a certain interval of $q_{\mathrm{CH}_{4}}$ beyond the range of the values studied experimentally. This in turn raises hopes that if we could implement a regime with the methane flow rate on the order of $0.1 \mathrm{~L} / \mathrm{min}$, the degree of conversion would increase to $28 \%$. The same results could be obtained by increasing the repetition rate of discharge pulses to $1 \mathrm{kHz}$ for a methane flow rate of $1 \mathrm{~L} / \mathrm{min}$. By increasing the pulse repetition rate to $3 \mathrm{kHz}$ for the same methane flow rate, we could reach a degree of conversion as high as $84 \%$. The implementation of basically attainable degrees of conversion involves modernization of the generator of high voltage pulses and the design of the discharger, which will form the basis of subsequent experimental investigation. It is evident that without special justification these increased degrees of conversion are looking rather as a wishful thinking.

It can be seen from Figure 16 that the energy value of the conversion is almost independent of the methane flow rate and amounts to approximately $5 \mathrm{eV} /$ molecule. Such energy value is close to record-low values for the atmospheric pressure (see, e.g., [25]).

The fact that the energy value of conversion is almost independent of the methane flow rate in the entire range of its variation in the experiment is an additional argument in favor of the possibility of a substantial increase in the degree of conversion due to passage to small values of $q_{\mathrm{CH}_{4}}$.

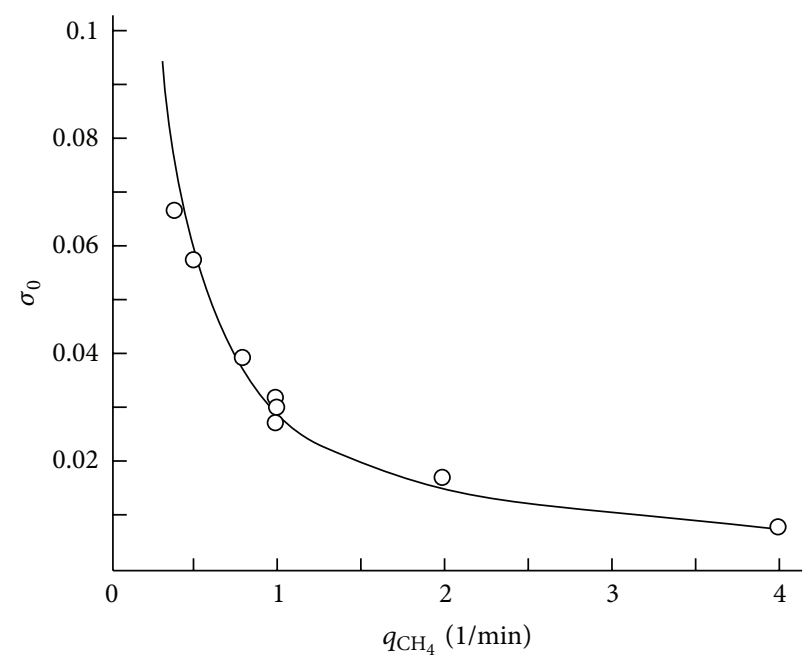

FIGURE 15: Dependence of the total degree of conversion of methane on its flow rate.

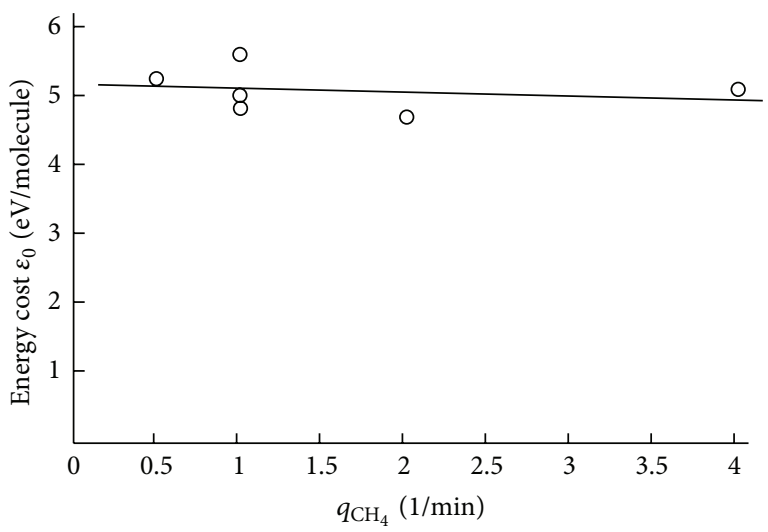

FIGURE 16: Dependence of the energy value of conversion of methane on its flow rate.

Analysis made in [26] shows that a high efficiency of methane conversion processes characteristic of the described technology is due to peculiarities contained just in discharges localized in an interelectrode gaps. Fast heating (up to $4000-5000 \mathrm{~K}$ ) of the gas propagating between the electrodes through the area occupied by microplasma leads to the effective decomposition of hydrocarbon. At the same time, fast cooling of the gas penetrating into the surrounding water is followed by quenching phenomena, and the level of the parent-gas decomposition does not change.

The low energy value of methane decomposition and the possibility of elevating the degree of conversion justify the application of the method of plasma-chemical action for solving the topical problem of recovery of natural blowouts of hydrocarbons. In this connection, the role of pyrolysis in the methane decomposition is of interest in its own right. If the contribution from reaction (4) is significant, it is expedient to determine the form and efficiency of the production of carbon accompanying the decomposition of methane. 
The experiments performed in accordance with the diagram in Figure 13 have shown that if the multispark discharge is initiated in water using $\mathrm{CH}_{4}$ as the bubble-forming gas, most carbon particles appearing in water as a result of plasma-chemical decomposition of methane precipitate.

Analysis of the precipitate shows that its main part is nanosize carbon. Figure 17 shows the characteristic size distribution of carbon particles as a function of the time of electric-discharge treatment of water, which was determined using Fotokor dynamic scattering spectrometer. The typical photograph of nanocarbon produced in the course of methane recovery by multispark discharge in the water is shown on the Figure 18.

The rate of production of nanosized particles in the discharge, which was determined by evaporation of the SSDprocessed liquid and weighing the precipitate, was about $35 \mathrm{mg} / \mathrm{h}$. This means that the energy value of production of nanocarbon upon decomposition of methane in the SSD is $0.3 \mathrm{~kW} \mathrm{~h} / \mathrm{g}$. The measured value is close to that obtained for arc discharges with carbon electrodes in water, in which carbon is formed in the liquid as a result of destruction of the electrodes [27, 28].

The structure of the precipitate was determined using a LAB RAM HR 800 Raman spectrometer from the Raman shift. Fractions of disordered graphite and carbon were detected.

\section{Water Cleaning of 2,4-Dichlorophenoxyacetic Additive}

Polychlorinated biphenyls (PCBs), among man-made pollutions, deserve particular attention. These compounds were synthesized in $1920 \mathrm{~s}$, and with their advent new materials with unique thermophysical and electrical insulating properties became available.

However, in spite of the presence of a number of unique properties, these compounds were withdrawn from industrial processes already in $1970 \mathrm{~s}$. This is due to the fact that PCBs were implicated in a number of incidents in different countries by causing mass intoxication and exerting a detrimental effect on the health of humans on a large scale.

The PCBs are no longer manufactured but remain in the environment, so that the search for ways of their destruction is one of the urgent problems of the day. At the General Physics Institute of RAS, experiments were carried out to examine possibility of electric discharge (SSD) in water as an efficient and inexpensive method for cleaning the manufacturing water of PCBs. Instead of a toxic PCB in our experiments, we used a 2,4-D dichlorophenoxyacetic acid (2,4-D). This material was chosen for plasmachemical decomposition, because the configuration of the 2,4$\mathrm{D}$ molecule somewhat resembles PCB. More exactly, the 2,4-D molecule, like the PCB congeners, contains a doubly chlorine-substituted benzene ring with attached acetic acid.

The experimental procedure was as follows. Two solid particles of 2,4-D (97\%) of weight $40 \mathrm{mg}$ were preliminarily dissolved in $10 \mathrm{~mL}$ of alcohol. The solution was poured into a polyethylene container with $5 \mathrm{~L}$ of distilled water. The acid

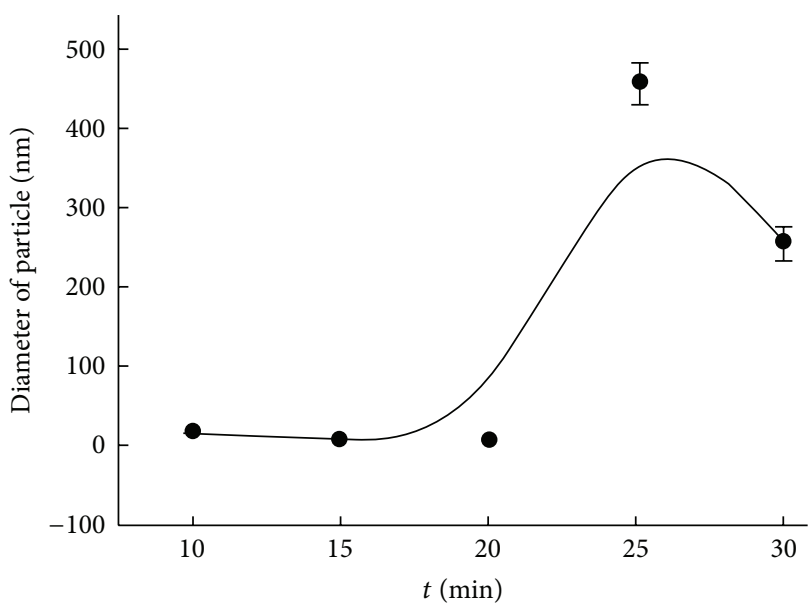

FIGURE 17: Dependence of the average size of carbon particles produced in the reactor on the time of electric discharge processing of methane.

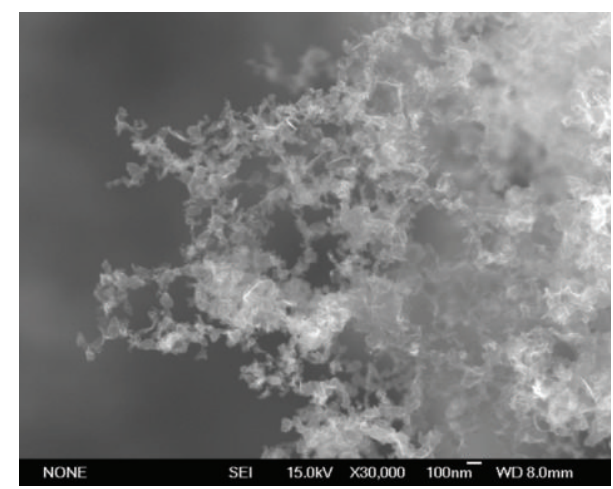

FIGURE 18: The typical photograph of nanocarbon produced in the course of methane recovery by multispark discharge in the water.

concentration in the container was estimated at $\sim 8 \mu \mathrm{g} \mathrm{cm}^{-3}$, that is, about 300 times larger than the maximum allowable ("permissible") concentration.

Decomposition of the acidic additive was accomplished using a multispark discharger mounted in a plexiglass reactor chamber of volume $V=15 \times 6 \times 4.5 \mathrm{~cm}^{3}$. The multispark discharger, which was placed on inside of the reactor cover, produced a discharge in water. The working gas passed through the discharger was oxygen.

Analysis of the SSD-processed solutions was conducted in the Laboratory of Analytic Environmental Toxicology at the Severtsov Institute of Ecology and Evolution of the Russian Academy of Sciences.

GC/MS (Gas chromatography/Mass spectrometry) analysis of solutions was performed by using a Finnigan TRACE GC Ultra gas chromatograph coupled with a Finnigan Polaris Q mass spectrometer (ion trap). This GC/MS system possessing ultra-high sensitivity allows detection of 2,4-D compound and its possible organic products of fragmentation with sensitivity $\sim 10^{-9} \mathrm{~g} \mathrm{~cm}^{-3}$.

All our experiments were conducted at fixed values of the initial 2,4-D concentration $N=8 \mu \mathrm{g} \mathrm{cm}^{-3}$ and solution volume $V=250 \mathrm{~cm}^{3}$. In all experiments, a sample of solution 
was taken from the reactor before processing in order that the initial 2,4-D concentration will be accurately known.

Data of GC/MS measurements ensure complete decomposition of 2,4-D (at the level of sensitivity $10^{-9} \mathrm{~g} \mathrm{~cm}^{-3}$ ) in all of the experiments when the processing time was longer than $150 \mathrm{~s}$ and the mean power of the high-voltage generator was $\sim 20 \mathrm{~W}$. These experiments give a conservative estimate of the efficiency of plasmachemical decomposition of the organic 2,4-D compound by the use of a multielectrode system excited electric discharge (SSD) in water. A characteristic dependence of the 2,4-D concentration on the duration of SSD processing is presented in Figure 19.

Almost complete ( $100 \%)$ decomposition of $2,4-\mathrm{D}$ a high-concentrated solution shows that the SSD processing will outperform the traditional reactors. From the experiments, it might be inferred that SSD working in the water containing about 300 maximum allowable concentration of 2,4D provides almost complete decomposition of liquid solution with expenditure of energy as low as $\sim 2 \cdot 10^{-3} \mathrm{kWh} / \mathrm{L}$. Accordingly, with a power source $\sim 1 \mathrm{~kW}$ it is possible to clean more than $0.5 \mathrm{~m}^{3}$ of water per hour.

We do not have a clear notion of what mechanism is dominant in the technological process of water cleaning of the 2,4-D additive. Special experiments have yet to be performed to construct a physicochemical model for electric-discharge destruction of the acid (and its decomposition fragments). However, we have good reason to believe that a leading part in destruction is played by plasma-chemical reactions occurring in SSD with the resulting formation of chemically active radicals and molecules.

\section{Conclusion}

A new electric-discharge system, which has been developed and tested at the GPI RAS, has a multitude of potential uses. Examples can be found in the present paper. A plasmachemical reactor of simple design using a multielectrode (multispark) discharger operating in aqueous medium may serve for efficient disinfection of microbially contaminated potable and waste water, conversion (recovery) of methane, destruction of acidic 2,4-D pollutant.

The SSD-based electrode system is capable of producing multiple microplasma formations in liquid medium at relatively low electrode voltages. Physical and chemical properties peculiar to this type of discharges have been studied experimentally. It is shown that these properties are controlled by the following four factors simultaneously acting upon the liquid (aqueous) medium:

(i) direct influence of electric-discharge plasma possessing a high electron density and relatively high temperatures of the gas and electron component,

(ii) exposure to intense UV radiation emitted by microplasma formations,

(iii) chemical action of chemically active radicals, atoms, and molecules produced in discharges and penetrated the water,

(iv) hydrodynamic action through cavitation bubbles.

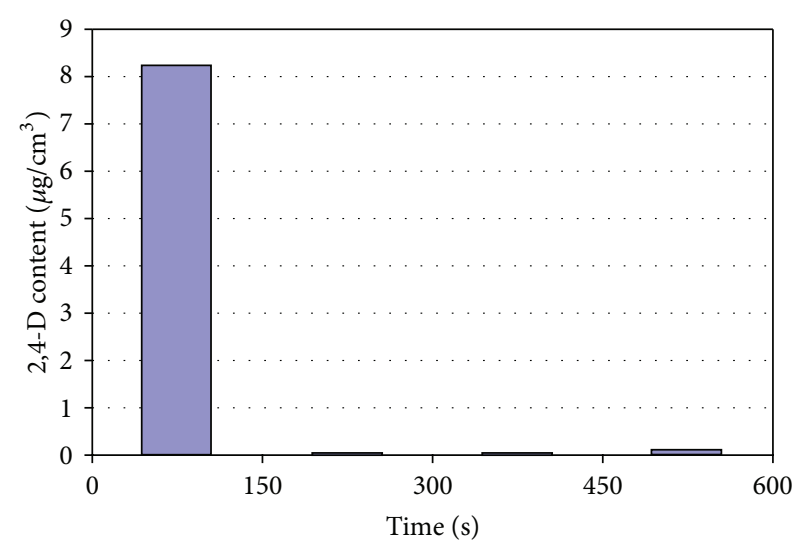

FIGURE 19: 2,4-D content as a function of time of water treatment by means of multispark discharge.

For each concrete application, the electric-discharge system may be modified in design so as to increase one or the other of these factors.

The experiments demonstrated high efficiency of multispark discharge in water for solving diversified environmental problems listed above. Note that the dominant mechanism in sterilization of potable and waste water was the biologically active UV radiation and generation of chemically active molecules (ozone, hydrogen peroxide). The achievement of encouraging results in conversion of natural hydrocarbons is credited to the immediate action of microplasma formation on the gas being treated. The success in the accomplishment of water cleaning of 2,4-D is attributed to plasmochemical mechanism of generating chemically active substances.

In conclusion, the multispark discharge in water is being used more and more. Thus, the action of SSD on the organic pollutions has been investigated in [29]. Decomposition of dissolved pentachlorophenol and parachlorophenol under multispark discharge action has been measured. Efficiency of reforming these phenols was as good as $1-2 \mathrm{~kJ} / \mathrm{mg}$.

\section{References}

[1] V. L. Goryachev, F. G. Rutberg, and V. N. Fedyukovich, "Electric-discharge method of water treatment. Status of the problem and prospects," Applied Energy, vol. 36, pp. 35-49, 1998.

[2] L. A. Yutkin, Electrohydroulic Effect and Industrial Application, Mashinostroenie, Leningrad, Russia, 1986.

[3] J. Sketchell, H.-G. Peterson, and N. Christofi, "Disinfection byproduct formation after biologically assisted GAC treatment of water supplies with different bromide and DOC content," Water Research, vol. 29, no. 12, pp. 2635-2642, 1995.

[4] F. X. R. Van Leeuwen, "Safe drinking water: the toxicologist's approach," Food and Chemical Toxicology, vol. 38, pp. 851-858, 2000.

[5] U. Von Gunten, A. Driedger, H. Gallard, and E. Salhi, "Byproducts formation during drinking water disinfection: a tool to assess disinfection efficiency?" Water Research, vol. 35, no. 8 , pp. 2095-2099, 2001.

[6] PCT, Treatment of Liquid International Patent Application no PCT/GB99/00755, 1999. 
[7] L. A. Kul'skii, O. S. Savchuk, and E. Yu. Deinega, Influence of Electron Field on Process of Water Sterilization, Nauk. Dumka, Kiev, Ukraine, 1980.

[8] E. M. Barkhudarov, I. A. Kossyi, M. I. Taktakishvili, N. Christofi, and V. Zadiraka Yu, "Multispark generation of plasma in liquids and its utilization in waste water treatment," in Proceedings of the 13th International Conference on Gas Discharges and their Applications, vol. 2, pp. 680-683, Strathclyde University, Glasgow, UK, 2000.

[9] A. M. Anpilov, E. M. Barkhudarov, Y. B. Bark et al., "Electric discharge in water as a source of UV radiation, ozone and hydrogen peroxide," Journal of Physics D, vol. 34, no. 6, pp. 993999, 2001.

[10] S. M. Korobeinikov and E. V. Yashin, "Bubble model for breakdown in water at pulsed voltage. Electric discharge in liquid and its industrial application, part 1, Nikolaev, Russia," 1988.

[11] V. L. Goryachev, A. A. Ufimtsev, and A. M. Khodakovskii, "Mechanism of electrode erosion in pulsed discharges in water with a pulse energy of 1 J," Technical Physics Letters, vol. 23, no. 5, pp. 386-387, 1997.

[12] A. M. Anpilov, E. M. Barkhudarov, N. K. Berezhetskaya et al., "Source of a dense metal plasma," Plasma Sources Science and Technology, vol. 7, no. 2, pp. 141-148, 1998.

[13] Y. B. Bark, E. M. Barkhudarov, Y. N. Kozlov et al., "Slipping surface discharge as a source of hard UV radiation," Journal of Physics D, vol. 33, no. 7, pp. 859-863, 2000.

[14] K. H. Becker, K. H. Schoenbach, and J. G. Eden, "Microplasmas and applications," Journal of Physics D, vol. 39, no. 3, pp. R55R70, 2006.

[15] A. M. Anpilov, N. K. Berezhetskaya, V. A. Kop'ev et al., "Explosive-emissive source of a carbon plasma," Plasma Physics Reports, vol. 23, no. 5, pp. 422-428, 1997.

[16] N. K. Berezhetskaya, V. A. Kop’ev, I. A. Kossyi, I. I. Kutuzov, and B. M. Tiit, "Explosive emission phenomena on a metal-hot plasma interface," Zhurnal Tekhnicheskoi Fizikiv, vol. 61, no. 2, pp. 179-184, 1991 (Russian).

[17] E. M. Barkhudarov, I. A. Kossyi, and M. I. Taktakishvili, "Distributed plasma generation in liquids," in Proceedings of 13th International Conference on Gas Discharges and their Applications, vol. 2, pp. 340-342, Strathclyde University, Glasgow, UK, 2000.

[18] C. G. Hatchard and C. A. Parker, "A new sensitive chemical actinometer. II. Potassium ferrioxalate as a standard chemical actinometer," Proceedings of the Royal Society A, vol. 235, no. 1203, pp. 518-536, 1956.

[19] V. V. Lunin, M. P. Popovich, and S. N. Tkachenko, Physical Chemistry of Ozone, Moscow State University Press, Moscow, Russia, 1998.

[20] J. H. Baxeudale, "The flash photolysis of water and aqueous solutions," Radiation Research, vol. 17, no. 3, pp. 312-326, 1962.

[21] B. N. Frog and A. P. Levchenko, Preparation of Water, Moscow State University Press, Moscow, Russia, 1996.

[22] A. M. Anpilov, E. M. Barkhudarov, N. Christofi et al., "Pulsed high voltage electric discharge disinfection of microbially contaminated liquids," Letters in Applied Microbiology, vol. 35, no. 1, pp. 90-94, 2002.

[23] A. M. Anpilov, E. M. Barkhudarov, N. Christofi et al., "The effectiveness of a multi-spark electric discharge system in the destruction of microorganisms in domestic and industrial wastewaters," Journal of Water and Health, vol. 2, no. 4, pp. 267277, 2004.
[24] A. I. Babaritskii, S. A. Demkin, V. K. Zhivotov et al., Plasmachemistry-91 (INKhS AN SSSRv), vol. 2, pp. 286-303, 1991.

[25] S. I. Gritsinin, P. A. Gushchin, A. M. Davydov, E. V. Ivanov, I. A. Kossyi, and M. A. Misakyan, "Conversion of methane in a coaxial microwave torch," Plasma Physics Reports, vol. 35, no. 11, pp. 933-940, 2009.

[26] A. M. Anpilov, E. M. Barkhudarov, N. K. Berezhetskaya et al., "Methane conversion in a multielectrode slipping surface discharge in the two-phase water-gas medium," Technical Physics, vol. 56, no. 11, pp. 1588-1592, 2011.

[27] N. Parkansky, O. Goldstein, B. Alterkop et al., "Features of micro and nano-particles produced by pulsed arc submerged in ethanol," Powder Technology, vol. 161, no. 3, pp. 215-219, 2006.

[28] N. Sano, "Low-cost synthesis of single-walled carbon nanohorns using the arc in water method with gas injection," Journal of Physics D, vol. 37, no. 8, p. L17, 2004.

[29] V. M. Shmelev, N. V. Evtyukhin, Y. N. Kozlov, and E. M. Barkhudarov, "Action of pulsed surface discharge on organic contaminants in water," Khimicheskaya Fizika, vol. 23, no. 9, pp. 77-85, 2004 (Russian). 

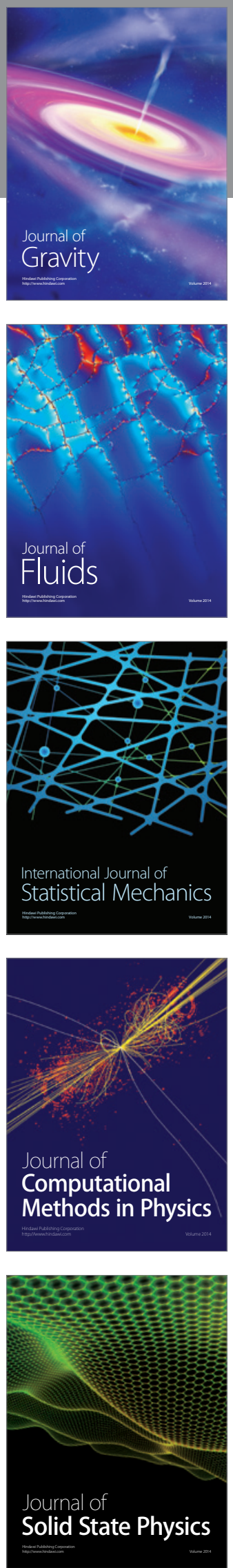

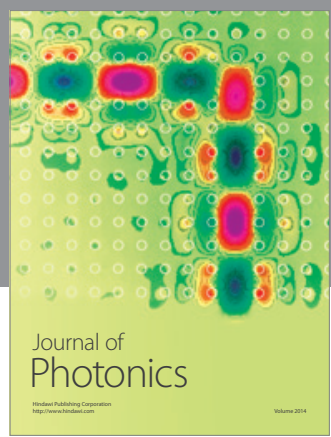

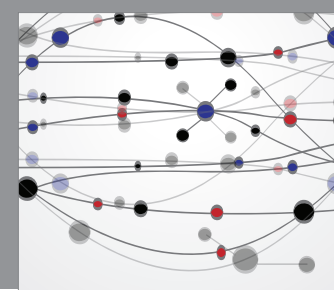

The Scientific World Journal

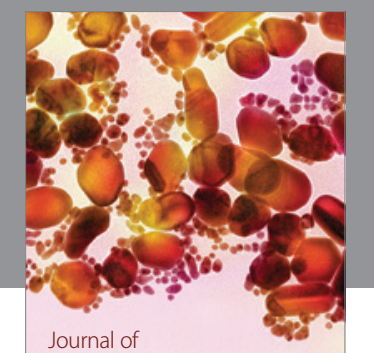

Soft Matter
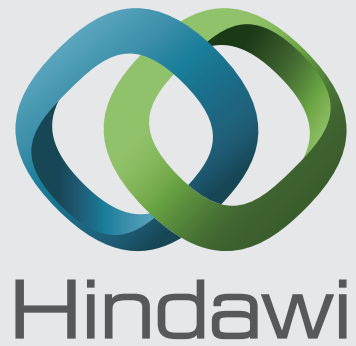

Submit your manuscripts at

http://www.hindawi.com
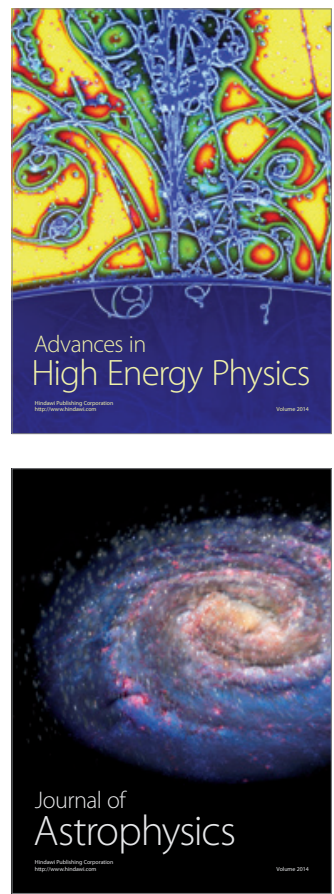
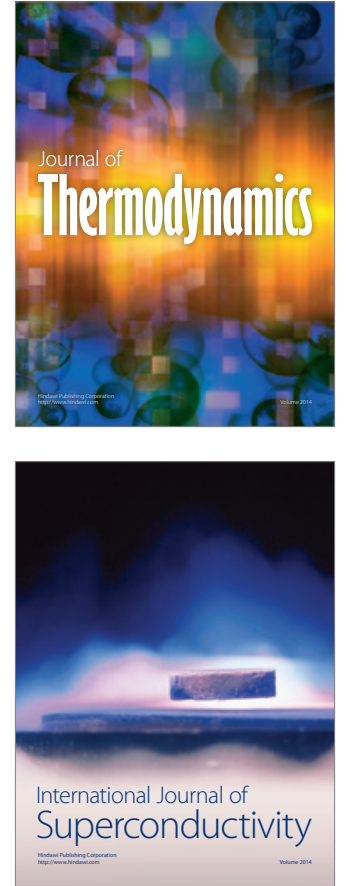
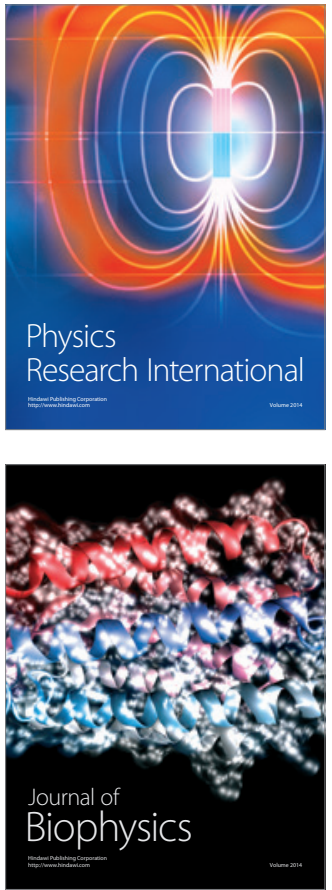
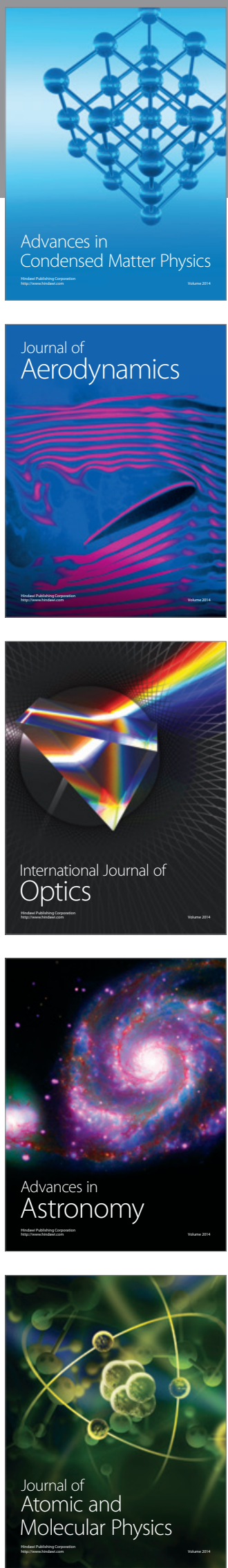